\title{
Üniversite Personelinin İşyerinde Engelliye Yönelik Tutumlarının Belirlenmesi
}

\author{
Hande Şahin ${ }^{a^{*}}$, İstar Cengiz ${ }^{b}$ \\ ${ }^{a}$ Kırıkkale Üniversitesi, Sağlık Bilimleri Fakültesi Sosyal Hizmet Bölümü, Kırıkale. \\ ${ }^{b}$ Kırıkkale Üniversitesi, Hukuk Fakültesi, Kırıkkale.
}

\begin{abstract}
$\ddot{O} z$
Üniversite personelinin işyerinde engelliye yönelik tutumların belirlemeyi amaçlayan bu çalışmaya Kırıkkale Üniversitesi Sağlık Bilimleri Fakültesi'nde ve Hukuk Fakültesi'nde görev yapan 115 akademik ve idari personel katılmıştır. Veri toplama aracı olarak Mamatoğlu, Dökmen ve Yıldırım (2015) tarafindan geliştirilen "İş Yerinde Engelliye Yönelik Tutumlar Ölçeği" kullanılmıştır. Sonuçların değerlendirilmesinde tanımlayıcı istatistikler, Kruskal Wallis H, Mann Whitney $U$ istatistik analiz yöntemleri kullanılmıştır. Araştırma sonucunda; üniversite personelinin işyerinde engelli bireye yönelik tutumlarının cinsiyete, eğitim düzeyine ve görev türüne göre değişiklik gösterdiğgi belirlenmiştir $(p<0.05)$.
\end{abstract}

Anahtar Kelimeler: Akademik Personel, Engelli Tutumu, İdari Personel, İşyeri, Üniversite

\section{Determination of University Staff's Attitudes towards the Disabled in the Workplace}

\begin{abstract}
This research which aimed the university staff's attitudes towards the disabled in the workplace was conducted with the participation of 115 academic and administrative staff members working at the Faculty of Law and Faculty of Health Science at Kirikkale University. In the study, the "Attitude Scale for Disability in the Workplace " which is developed by Mamatoğlu, Dökmen ve Yıldırım (2015) was used as the data collection instruments. Descriptive statistics, the Kruskal-Wallis test and the Mann-Whitney U test were used in statistical analysis. The study results revealed significant differences in the the attitudes of the university staff towards the disabled individual with respect to gender, education level and duty type $(\mathrm{p}<0.05)$.
\end{abstract}

Keywords: Academic Staff, Disability Attitudes, Administrative Staff, Workplace, University

\section{GIRIş}

Dünyada ve Türkiye'de dezavantajll, engelli bireylere yönelik olumlu gelişmeler, yasal düzenlemeler ile sağlanmıştır. Özellikle yirminci yüzyılın ikinci yarısı ile birlikte gerek uluslararası örgütler, gerekse de ulusal hükumetler konunun önemini daha iyi kavrayabilmişlerdir. Ulusal ve uluslararası sosyal politikalar üreterek yasal düzenlemeler ile dezavantajlıların, özellikle de engellilerin hayata daha sıkı sarılmaları, temel insan haklarından yararlanabilmeleri ve her şeyden önemlisi üreten ve mutlu bireyler olarak ülke değerlerine katkıda bulunur hale gelmelerini sağlamak çağdaş devletlerin anayasal öncelikleri arasında yer almıştır (Küçükali, 2014). Bir kişinin engelli olması bu haklarından vazgeçmesini gerektirmemektedir. Gerçekte engelli bireyler istihdam edilmeye, sağlam işgücünden daha fazla ihtiyaç duymaktadır. Çünkü söz konusu bireylerin, engellilikleri sebebiyle oluşacak sağlık masraflarını 
karşılayabilmesini sağlayacak, aynı zamanda üretmeden tüketen bu nüfusun ekonomik kaynak üzerindeki baskısı ortadan kalkacaktır. Yeteneğine uygun işlerde istihdam edilen engelli birey, bağımsız olarak hayatını sürdürebilecek, kendine güven ve saygı duyabilecektir. Tüm bunların yanında engellilerin istihdam edilmesi sosyal devletin görevidir (Gönülaçan, 2016).

Kalkınma planlarına engelli istihdamı açısından baktığımızda, istihdam konusunda engellilere ilk atıf 1990 - 1994 yılları için yürürlükte bulunan altıncı kalkınma planında olmuştur. Bu plan içerisinde istihdam ile ilgili ilke ve politikalar içerisinde; "İşgücü piyasasına girişte zorluklarla karşılaşan özürlüler ve eski hükümlülerin problemlerini giderici tedbirler alınacaktı", ifadesine yer verilmiştir. Daha sonra 2001 2005 yılları için hazırlanan sekizinci istihdam planında da, altıncı kalkınma planında olduğu gibi engellilere yönelik yeni hedefler belirlenmiştir. Engellilerin işsiz kalmalarını önleyecek tedbirlerin alınacağına vurgu yapılmıştır (Orhan,2013). Bu bağlamda engelli kişilerin devlet memuru olarak istihdamları Devlet Personel Başkanlığ1 koordinasyonundaki ilgili kamu kurum ve kuruluşları tarafından yapılmaktadır. Engellilerin işçi olarak istihdamları ise Türkiye İş Kurumu tarafından yapılmaktadır. Engelli kadrosuna devlet memuru olarak atanmak için öncelikle yapılacak sinavlara girmek gerekmektedir. Her kamu kurumu, engelli kadrosuna memur almak için kendisi sınav açmaktadır. Devlet memurluğuna ilişkin sınav duyuruları Devlet Personel Başkanlığınca yapılmakta olup Resmi Gazete ve ilgili kurumun Web sitesinde yayımlanmaktadır. 4857 sayılı İş Kanununun "Engelli ve eski hükümlü çalıştırma zorunluluğu" kenar başlıklı 30. maddesine göre; "(Değişik: 15/5/2008-5763/2 md.) işverenler, elli veya daha fazla işçi çalıştırdıkları özel sektör işyerlerinde yüzde üç engelliyi, kamu işyerlerinde ise yüzde dört engelli işçiyi meslek, beden ve ruhi durumlarına uygun işlerde çalıştırmakla yükümlüdürler." (İşs Kanunu,2003). Aynı il sınırları içinde birden fazla işyeri bulunan işverenin bu kapsamda çalıştırmakla yükümlü olduğu işçi sayısı, toplam işçi sayısına göre hesaplanmaktadır (Kavaklı ve Özkara, 2012).

İstihdam alanında sahip oldukları bu haklara rağmen engelliler, hem istihdam öncesinde hem de istihdam sonrasında olumsuz tutumlarla karşılaşmaktadırlar. Engelliler, istihdam öncesinde yeterli eğitim ve deneyim fırsatları verilmemesi ve istihdam sonrasında da olumsuz işveren ve çalışan davranışları ile karşılaşmaları biçiminde olumsuz tutumlara ve ayrımcılığa maruz kalmaktadırlar. Ayrıca işe alma sürecinde karşılaştıkları olumsuzluklardan da söz edilebilir. İşyerinde engelliler özelliklerine, yeteneklerine, eğitimlerine uygun işlerde çalıştırılmamakta, gereken iş eğitiminden de mahrum bırakılmaktadırlar; genellikle vasıfsız ve düşük statülü işlerde istihdam edilmektedirler. Pek çok engelli ise, çalışma gücüne ve isteğine sahip olduğu ve çalıştığında da yeterli başarıyı gösterdiği halde, önyargılar nedeniyle çalışma imkanı bulamamaktadır (Mamatoğlu ve ark., 2015). Nitekim yapılan literatür taramasında da özel sektörde çalışan engelli bireylere yönelik çalışmalara rastlanırken, bu çalışmalarda engelli bireylere yönelik olumsuz tutumların var olduğu belirlenmiştir (Akardere, 2005, Baybora, 2006, Kleynhans ve Kotze, 2010, Mansour, 2009, Mamatoğlu 
ve ark., 2015). Bu nedenle bu çalışma üniversite personelinin işyerinde engelliye yönelik tutumlarını belirlemek amacıyla planlanmış ve yürütülmüştür.

\section{METODOLOJi}

Üniversite personelinin işyerinde engelliye yönelik tutumlarını belirlemeyi amaçlayan bu çalışmanın evrenini Kırıkkale Üniversitesi Sağlık Bilimleri Fakültesi ve Hukuk Fakültesi'nde çalışan akademik ve idari personel oluşturmaktadır. Araştırmada zaman maliyet vb. kısıtlardan dolayı olasılıklı örnekleme yöntemlerinden sistematik örnekleme yöntemi kullanılmış ve toplam 115 akademik ve idari çalışan örneklem grubunu oluşturmuştur

\subsection{Verilerin Toplanmas1}

Çalışmada, veri toplama yöntemi olarak anket tekniği kullanılmıştır. Anket demografik bilgilerin yer aldığ 1 birinci bölüm ile Mamatoğlu, Dökmen ve Yıldırım (2015) tarafından geliştirilen "İş Yerinde Engelliye Yönelik Tutumlar Ölçeği"nin yer aldığ1 ikinci bölümden oluşmaktadır. İş Yerinde Engelliye Yönelik Tutumlar Ölçeği: Ölçek, likert tarzı 5 dereceli (1: kesinlikle katılmıyorum - 5: Kesinlikle katılıyorum) 47 maddeden oluşmaktadır. Ölçeğin "engelli istihdamına genel yaklaşım” (20 madde), "engellilerin iş ortamına ve işe uyumuna ilişkin alg1" (toplam 15 madde) ve "çalışan engellinin ve yaptığ toplam 47 maddeden oluşan üç faktörlü bir yapısı bulunmaktadır. "İş Yerinde Engelliye Yönelik Tutumlar Ölçeği"nden alınabilecek en düşük puan 47, en yüksek puan ise $235^{\prime}$ tir.

\subsection{Verilerin Değerlendirilmesi}

Verilerin analizi SPSS 21.0 programı ile yapılmıştır. Analizlerde uygun testin seçilmesinde normallik analizi sonucuna göre karar verilmiştir. Analiz sonucunda ölçek puanının normal dağılım göstermediği belirlenmiş ve bu gerekçe ile parametrik olmayan test tekniklerinin kullanılmasına karar verilmiştir (Büyüköztürk, 2017). İki gruplu değişkenlerin ölçek puanları açısından karşılaştırılmasında Mann-Whitney U Testi kullanılırken üç ve daha fazla gruplu değişkenlerin karşılaştırılmasında KruskalWallis H Testi kullanılmıştır.

\section{BULGULAR VE TARTIŞMA}

Çalışmada katılımcılardan 30 yaş ve altı olanların oranı \%35,6; 31-40 yaş arası olanların oranı $\% 38,3 ; 41$ yaş ve üstü olanların oranı $\% 26,1$; kadın olanların oranı $\% 57,4$ iken erkeklerin oranı \%42,6; eğitim durumu lise olanların oranı $\% 7,8$; üniversite olanların oranı \%20,0; yüksek lisans olanların oranı $\% 29,6$; doktora olanların oranı $\% 42,6$ 'dir (Tablo 1).

Katılımcılardan idari görevi olanların oranı \%17,4 iken akademik görevi olanların oranı \%82,6'dir. Araştırmada, araştırma görevlisi olanların oranı \%47,0; öğretim görevlisi olanların oranı \%1,7; yardımcı doçent doktor olanların oranı \%25,2; doçent doktor olanların oranı $\% 4,3$; profesör doktor olanların oranı $\% 4,3$; idari görevde çalışanların oranı \%17,4'tür (Tablo 1). 
Tablo 1. Araştırmaya Katılan Akademik ve İdari Personelin Demografik Özelliklerine Göre Dağılımı

\begin{tabular}{llcc}
\hline & & $\mathrm{n}$ & $\%$ \\
\hline \multirow{4}{*}{ Yaşınız } & 30 yaş ve altı & 41 & 35,6 \\
& 31-40 yaş arası & 44 & 38,3 \\
& 41 yaş ve üstü & 30 & 26,1 \\
\hline \multirow{2}{*}{ Cinsiyetiniz } & Kadın & 66 & 57,4 \\
& Erkek & 49 & 42,6 \\
\hline \multirow{4}{*}{ Eğitim Durumunuz } & Lise & 9 & 7,8 \\
& Üniversite & 23 & 20,0 \\
& Yüksek lisans & 34 & 29,6 \\
\multirow{2}{*}{ Görev türü } & Doktora & 49 & 42,6 \\
\hline \multirow{5}{*}{ Ünvan } & İdari & 20 & 17,4 \\
& Akademik & 95 & 82,6 \\
\hline & Araştırma Görevlisi & 54 & 47,0 \\
& Öğretim Görevlisi & 2 & 1,7 \\
& Yardımcı Doçent Doktor & 29 & 25,2 \\
& Doçent Doktor & 5 & 4,3 \\
& Profesör Doktor & 5 & 4,3 \\
& İdari & 20 & 17,4 \\
\hline
\end{tabular}

Araştırmaya alınan üniversite akademik ve idari personelin işyerinde engelli bireylere yönelik tutumlarının genel olarak orta düzeyin üzerinde olumlu olduğu belirlenmiştir (X=3,68). Eratay ve Çetin'in (2013) çalışmalarında da işverenlerin engelli çalışanlara yönelik genel orta düzeyde olumlu olduğu belirlenmiştir. İşyerinde engelli bireylere yönelik tutumların orta düzeyde olması çalışanların engellilere karşı önyargılarından biraz uzaklaştıklarının ve ayrımcılık yapmadıklarının göstergesi olabilir.

Araştırma kapsamına alınan üniversite personelinin iş yerinde engelliye yönelik tutumlarının yaşa göre karşılaştırılması Tablo 2'de verilmiştir.

Tablo 2. Araştırmaya Katılan Akademik ve İdari Personelin “İş Yerinde Engelliye Yönelik Tutumlar Ölçeği”" Puanlarının Yaşa Göre Karşılaştırılması

\begin{tabular}{|c|c|c|c|c|c|}
\hline Yaşınız & & $\mathrm{n}$ & Sira Ort. & $\mathrm{X}^{2} / \mathrm{F}$ & $\mathrm{p}$ \\
\hline \multirow{3}{*}{$\begin{array}{l}\text { Engelli İstihdamına Genel } \\
\text { Yaklaşım }\end{array}$} & 30 yaş ve altı & 41 & 62,84 & \multirow{3}{*}{4,031} & \multirow{3}{*}{ 133 } \\
\hline & $31-40$ yaş arası & 44 & 60,56 & & \\
\hline & 41 yaş ve üstü & 30 & 47,63 & & \\
\hline \multirow{3}{*}{$\begin{array}{l}\text { Engellilerin İş̧ Ortamına ve İşe } \\
\text { Uyumuna İlişkin Alg1 }\end{array}$} & 30 yaş ve altı & 41 & 63,65 & \multirow{3}{*}{3,845} & \multirow{3}{*}{, 146 } \\
\hline & $31-40$ yaş arası & 44 & 59,41 & & \\
\hline & 41 yaş ve üstü & 30 & 48,22 & & \\
\hline \multirow{3}{*}{$\begin{array}{l}\text { Çalışan Engellinin ve Yaptığın } \\
\text { İşin Algılanan Niteliği }\end{array}$} & 30 yaş ve altı & 41 & 62,02 & \multirow{3}{*}{4,947} & \multirow{3}{*}{, 084} \\
\hline & $31-40$ yaş arası & 44 & 62,17 & & \\
\hline & 41 yaş ve üstü & 30 & 46,38 & & \\
\hline
\end{tabular}


Araştırmaya katılan akademik ve idari personelin "İş Yerinde Engelliye Yönelik Tutumlar Ölçeği" alt boyutları ile yaş grupları arasında istatistiksel olarak anlamlı farklılık bulunmamaktadır $(p>0,05)$. İş yerinde engelli bireye karşı tutumların incelendiği Eratay ve Çetin (2013)'in ve Aile ve Sosyal Politikalar Bakanlığı'nın (2011) çalışmalarında da benzer bulgular elde edilmiş olup, araştırmaya katılanların yaşları ile engelli çalışana yönelik tutumları arasında bir ilişki bulunmamıştır. Bu durum işyerinde engelli bireye yönelik tutumların belirlenmesinde yaşın önemli bir faktör olmadığı sonucunu düşündürmektedir.

Araştırmaya alınan üniversite personelinin iş yerinde engelliye yönelik tutumlarının cinsiyete göre karşılaştırılması Tablo 3 'te verilmiştir.

Tablo 3. Araştırmaya Katılan Akademik ve İdari Personelin “İş Yerinde Engelliye Yönelik Tutumlar Ölçeği” Puanlarının Cinsiyete Göre Karşılaştırılması

\begin{tabular}{|c|c|c|c|c|c|}
\hline Cinsiyetiniz & & $\mathrm{n}$ & Sira Ort. & $\mathrm{U} / \mathrm{t}$ & $\mathrm{p}$ \\
\hline \multirow{2}{*}{$\begin{array}{l}\text { Engelli İstihdamına Genel } \\
\text { Yaklaşım }\end{array}$} & Kadın & 66 & 66,36 & \multirow{2}{*}{1065,500} & \multirow{2}{*}{, $002^{*}$} \\
\hline & Erkek & 49 & 46,74 & & \\
\hline \multirow{2}{*}{$\begin{array}{l}\text { Engellilerin İş Ortamına ve İşe } \\
\text { Uyumuna İlişkin Alg1 }\end{array}$} & Kadın & 66 & 66,98 & \multirow{2}{*}{1024,500} & \multirow{2}{*}{, $001^{*}$} \\
\hline & Erkek & 49 & 45,91 & & \\
\hline \multirow{2}{*}{$\begin{array}{l}\text { Çalışan Engellinin ve Yaptığın } \\
\text { I̧şin Algılanan Niteliği }\end{array}$} & Kadın & 66 & 66,12 & \multirow{2}{*}{1081,000} & \multirow{2}{*}{, $002^{*}$} \\
\hline & Erkek & 49 & 47,06 & & \\
\hline
\end{tabular}

Kadın ile erkek grupları arasında Engelli İstihdamına Genel Yaklaşım puanı açısından istatistiksel olarak anlamlı farklılık bulunmaktadır $(\mathrm{p}<0,05)$. Kadınların puan sıra ortalamaları 66,36 iken erkeklerin ortalamaları 46,74'tür. Buna göre kadınların Engelli İstihdamına Genel Yaklaşım puan sıra ortalamaları erkeklere göre daha yüksektir. Bu durum kadınların engelli istihdamına ilişkin tutumlarının erkeklere göre daha olumlu olduğunu göstermektedir.

Kadın ile erkek grupları arasında Engellilerin İş Ortamına ve İşe Uyumuna İlişkin Algı puanı açısından istatistiksel olarak anlamlı farklılık bulunmaktadır $(\mathrm{p}<0,05)$. Kadınların katılım düzeyleri ortalamaları 66,98 iken erkeklerin ortalamaları 45,91'dir. Buna göre kadınların İş Ortamına ve İşe Uyumuna İlişkin Algı puanına katılım düzeyleri erkeklere göre daha yüksektir.

Kadın ile erkek grupları arasında Çalışan Engellinin ve Yaptığın İşin Algılanan Niteliği puanı açısından istatistiksel olarak anlamlı farklılık bulunmaktadır $(\mathrm{p}<0,05)$. Kadınların katılım düzeyleri ortalamaları 66,12 iken erkeklerin ortalamaları 47,06'dır. Buna göre kadınların Çalışan Engellinin ve Yaptığın İşin Algılanan Niteliği puanına katılım düzeyleri erkeklere göre daha yüksektir. 
Satcher ve Dooley Dickey (1992), işverenlerin engelli bireylerin işe alınmasına ve bu bireylerle birlikte çalışılmasına yönelik tutumlarında işverenin cinsiyet değişkeninin etkili olduğunu belirtmişlerdir.

Akardere (2005) tarafından işverenlerin engelli çalışanlara yönelik tutumlarını belirlemek amacıyla yaptığı çalışmada engelli çalışana yönelik tutumları ve cinsiyetleri arasında anlamlı bir farklılık bulunmuş. Ancak yaptığı çalışmada; bizim çalışmamızdan farklı olarak erkeklerin engelli çalışana yönelik tutumlarının kadınlardan fazla olduğu bulunmuştur. Bulgular arasındaki bu farklılık Akardere'nin çalışmasında erkeklerin oran olarak fazla olmasından kaynaklanmış olabilir.

Araştırmaya katılan akademik ve idari personelin iş yerinde engelliye yönelik tutumlarının eğitim düzeyine göre karşılaştırılması Tablo 4 'te verilmiştir.

Tablo 4. Araştırmaya Katılan Akademik ve İdari Personelin "İş Yerinde Engelliye Yönelik Tutumlar Ölçeği” Puanlarının Eğitim Düzeyine Göre Karşılaştırılması

\begin{tabular}{|c|c|c|c|c|c|}
\hline Eğitim Düzeyi & & $\mathrm{n}$ & Sira Ort. & $\mathrm{X}^{2} / \mathrm{F}$ & $\mathrm{p}$ \\
\hline \multirow{4}{*}{$\begin{array}{l}\text { Engelli İstihdamına Genel } \\
\text { Yaklaşım }\end{array}$} & Lise & 12 & 25,42 & \multirow{4}{*}{16,138} & \multirow{4}{*}{, $001^{*}$} \\
\hline & Üniversite & 20 & 51,18 & & \\
\hline & Yüksek Lisans & 34 & 60,44 & & \\
\hline & Doktora & 49 & 67,07 & & \\
\hline \multirow{4}{*}{$\begin{array}{l}\text { Engellilerin İş Ortamına ve } \\
\text { İşe Uyumuna İlişkin Algı }\end{array}$} & Lise & 12 & 22,75 & \multirow{4}{*}{20,781} & \multirow{4}{*}{, $000^{*}$} \\
\hline & Üniversite & 20 & 48,05 & & \\
\hline & Yüksek Lisans & 34 & 60,38 & & \\
\hline & Doktora & 49 & 69,04 & & \\
\hline \multirow{4}{*}{$\begin{array}{l}\text { Çalışan Engellinin ve } \\
\text { Yaptığı İşin Algılanan } \\
\text { Niteliği }\end{array}$} & Lise & 12 & 15,75 & \multirow{4}{*}{25,046} & \multirow{4}{*}{, $000^{*}$} \\
\hline & Üniversite & 20 & 53,73 & & \\
\hline & Yüksek Lisans & 34 & 59,68 & & \\
\hline & Doktora & 49 & 68,93 & & \\
\hline
\end{tabular}

$\mathbf{P}<0.05$

Eğitim düzeyi farklı olan gruplar arasında Engelli İstihdamına Genel Yaklaşım puanı açısından istatistiksel olarak anlamlı farklılık bulunmaktadır $(p<0,05)$. Araştırmaya alınanların öğrenim düzeyi yükseldikçe Engelli İstihdamına Genel Yaklaşım puanları da artmaktadır.

Eğitim düzeyi farklı olan gruplar arasında Engellilerin İş Ortamına ve İşe Uyumuna İlişkin Algı puanı açısından istatistiksel olarak anlamlı farklılık bulunmaktadır $(p<0,05)$. Araştırmaya alınanların öğrenim düzeyi yükseldikçe Engellilerin İş Ortamına ve İşe Uyumuna İlişkin Algı puanları da artmaktadır.

Eğitim düzeyi farklı olan gruplar arasında Engellilerin Çalışan Engellinin ve Yaptığın İşin Algılanan Niteliği puanı açısından istatistiksel olarak anlamlı farklılık bulunmaktadır $(p<0,05)$. Araştırmaya alınanların öğrenim düzeyi yükseldikçe Engellilerin Çalışan Engellinin ve Yaptığın İşin Algilanan Niteliği puanları da artmaktadır. 
Aile ve Sosyal Politikalar Bakanlığı (2011) tarafından işyerinde engelli çalışana yönelik tutumların incelendiği çalışmada işverenin eğitim düzeyinin engelli istihdamına yönelik tutumu ile anlamlı bir ilişkisinin olmadığı belirlenmiştir. Buna karşın, Özmen (1996)'in, işverenlerin engelli bireylerin işe alınması ve birlikte çalışılmasına yönelik tutumlarını çeşitli değişkenler açısından karşılaştırdığı çalışmasında, işverenin eğitim düzeyi ile engelli bireylerin işe alınmasına yönelik tutumları arasında anlamlı bir ilişkinin olduğunu ortaya çıkarmıştır.

Araştırmaya katılan akademik ve idari üniversite personelinin iş yerinde engelliye yönelik tutumlarının görev türüne göre karşılaştırılması Tablo 5 'te verilmiştir.

Tablo 5. Araştırmaya Katılan Akademik ve İdari Personelin “İş Yerinde Engelliye Yönelik Tutumlar Ölçeği” Puanlarının Görev Türüne Göre Karşılaştırılması

\begin{tabular}{|c|c|c|c|c|c|}
\hline Görev türü & & $\mathrm{n}$ & Sira Ort. & $\mathrm{u} / \mathrm{t}$ & $\mathrm{p}$ \\
\hline \multirow{2}{*}{$\begin{array}{l}\text { Engelli İstihdamına Genel } \\
\text { Yaklaşım }\end{array}$} & İdari & 20 & 25,33 & \multirow{2}{*}{296,500} & \multirow[t]{2}{*}{, $000^{*}$} \\
\hline & Akademik & 95 & 64,88 & & \\
\hline \multirow{2}{*}{$\begin{array}{l}\text { Engellilerin İş Ortamına ve İşe } \\
\text { Uyumuna İlişkin Alg1 }\end{array}$} & İdari & 20 & 23,90 & \multirow{2}{*}{268,000} & \multirow[t]{2}{*}{, $000^{*}$} \\
\hline & Akademik & 95 & 65,18 & & \\
\hline \multirow{2}{*}{$\begin{array}{l}\text { Çalışan Engellinin ve Yaptı̆̆ın İşin } \\
\text { Algılanan Niteliği }\end{array}$} & İdari & 20 & 20,98 & \multirow{2}{*}{209,500} & \multirow{2}{*}{, $000^{*}$} \\
\hline & Akademik & 95 & 65,79 & & \\
\hline
\end{tabular}

${ }^{*} \mathrm{p}<0.05$

İdari ile akademik görevde olan gruplar arasında Engelli İstihdamına Genel Yaklaşım puanı açısından istatistiksel olarak anlamlı farklılık bulunmaktadır $(\mathrm{p}<0,05)$. İdari görevde olanların katılım düzeyleri ortalamaları 25,33 iken akademik görevde olanların ortalamaları 64,88' dir. Buna göre akademik görevde olanların idari görevde olanlara Engelli İstihdamına Genel Yaklaşım puanına katılım düzeyleri daha yüksektir.

İdari ile akademik görevde olan gruplar arasında Engellilerin İş Ortamına ve İşe Uyumuna İlişkin Alg1 puanı açısından istatistiksel olarak anlamlı farklılık bulunmaktadır $(\mathrm{p}<0,05)$. İdari görevde olanların katılım düzeyleri ortalamaları 23,90 iken akademik görevde olanların ortalamaları 65,18' dir. Buna göre akademik görevde olanların idari görevde olanlara Engellilerin İş Ortamına ve İşe Uyumuna İlişkin Alg1 puanına katılım düzeyleri daha yüksektir.

İdari ile akademik görevde olan gruplar arasında Çalışan Engellinin ve Yaptığın İşin Algılanan Niteliği puanı açısından istatistiksel olarak anlamlı farklılık bulunmaktadır $(\mathrm{p}<0,05)$. İdari görevde olanların katılım düzeyleri ortalamaları 20,98 iken akademik görevde olanların ortalamaları 65,79'dur. Buna göre akademik görevde olanların idari görevde olanlara göre Çalışan Engellinin ve Yaptığın İşin Algılanan Niteliği puanına katılım düzeyleri daha yüksektir.

Her üç alt ölçekte de akademik personelin işyerinde engelli bireye yönelik tutumları idari personelden yüksek bulunmuştur. Bu durum akademik personelin 
gerek eğitim düzeyinin, gerekse engelli bireylerin ihtiyaç ve isteklerine yönelik farkındalığının fazla olmasından kaynaklanmış olabilir.

\section{SONUÇ VE ÖNERILER}

Yapılan araştırmada üniversite akademik ve idari personelin işyerinde engelli bireylere yönelik tutumlarının genel olarak orta düzeyin üzerinde olumlu olduğu saptanmıştır. Personelinin işyerinde engelli bireye yönelik tutumları ile cinsiyete, eğitim düzeyi ve görev türü arasında anlamlı bir ilişki belirlenmiştir. $(p<0.05)$. Araştırma sonucunda elde edilen bulgular sonucunda şu önerilerde bulunulabilir;

- Engelli dostu istihdam politikaları geliştirilmelidir,

- Engellilere profesyonel meslekler kazandırmak için eğitim hayatında, kamusal alanda ve yasal mevzuatta düzenlemeler yapılmalıdır,

- Araştırma bulgularının genellenebilirliğini arttırmak için araştırma, farklı çalışanlar, farklı iş alanları ve farklı araştırmacılar tarafından yinelenebilmelidir,

- Eğitimler yardımıyla engellilere ilişkin yanlış bilgilerin giderilmesi, onlarla sosyal temasın kolaylaştırması sağlanmalıdır.

\section{KAYNAKÇA}

Aile ve Sosyal Politikalar Bakanlığı Özürlü ve Yaşlı Hizmetleri Genel Müdürlüğü(2011). İşgücü piyasasının özürlüler açısından analizi. Mattek Matbaacılık, Ankara.

Akardere, S.S. (2005). İşverenlerin engelli çalışanlara yönelik tutumları. Marmara Üniversitesi Eğitim Bilimleri Enstitüsü Yayımlanmamış Yüksek Lisans Tezi.

Baybora D. (2006). Çalışma hayatında özürlülere karşı ayrımcılık, Sosyal Siyaset Konferansları Dergisi, 51: 229-269.

Büyüköztürk, Ş. (2017). Sosyal bilimler için veri analizi el kitabı. Pegem Akademi, Ankara.

Eratay, E. ve Çetin Eldeniz, M. (2013). “Bolu İlindeki İşverenlerin Engelli Çalışanlara Yönelik Tutumları", Kastomonu Eğitim Dergisi 21 (4), 1681-1694.

Gönülaçan, A. (2016). Engelli istihdamına yönelik işveren tutumları: Trabzon örneği. AİBÜ Sosyal Bilimler Enstitüsü Dergisi, 16 (3):111-130

İş Kanunu (2013). http://dosya.isvesosyalguvenlik.com/mevzuat/m146.pdf

Kavaklı, U., Özkara, E. (2012). Kişisel, sosyal ve iş hayatında özürlü bireylere tanınan haklar ve özürlü olguların medikolegal değerlendirmesi. DEÜ Tıp Fakültesi Dergisi 26 (1): 65-74

Kleynhans R. ve Kotze M. (2010). Managers' and employees' attitudes towards people with physical disabilities in the workplace. Tydskrif vir Geesteswetenskappe, 50(3): 404-417.

Küçükali, A. (2014). Engellilere uygulanan sosyal politikaların değerlendirilmesi: Atatürk Üniversitesi örneği. Kırıkkale Üniversitesi Sosyal Bilimler Dergisi 4 (1): 59-86.

Mamatoğlu, N., Yaşın Dökmen, Z., Yıldırım, F. (2015). İşyerinde engelliye yönelik tutumlar ölçeği, Hacettepe Üniversitesi Eğitim Fakültesi Dergisi 32 (2): 183-204.

Mansour (2009). Employers' attitudes and concerns about the employment of disabled people. International Review of Business Research Papers. 5(4): 209-218 
Orhan, S. (2013). Türkiye'de özürlü dostu istihdam politikaları (durum analizi ve öneriler) T.C. Çalışma ve Sosyal Güvenlik Bakanlığı Çalışma ve Sosyal Güvenlik Eğitim ve Araştırma Merkezi Yayınları Yayın No: 35 Ankara

Özmen, E.S. (1996). İşverenlerin engelli bireylerin işe alınması ve birlikte çalışılmasına yönelik tutumlarının çeşitli değişkenler açısından karşılaştırılması. Ankara Üniversitesi Sosyal Bilimler Enstitüsü Yayımlanmamış Yüksek Lisans Tezi.

Satcher, J. ve Dooley-Dickey , K. (1992). Attitudes of human resource management students toward persons with disabilities.rehabilitation, Counseling Bulletin 35 (4):248-252. 